\title{
Management of isolated distal end of radius fracture in pediatric age group: An observational study
}

\author{
Vishwas S Phadke ${ }^{1}$, Ajaykumar R Allamwar ${ }^{2}$, Vaibhav V Antrolikar ${ }^{3}$ \\ ${ }^{1}$ Associate Professor, ${ }^{2,3}$ Assistant Professor, Department of Orthopedics. SSPM Medical college and Lifetime hospital, \\ A.P. Padve, Taluka Kudal, District Sindhudurg
}

\section{A B STR A C T}

Background: Fractures of the distal radius are one of the common fractures for which pediatric orthopedic consultations are sought. The usual mechanism of injury is fall on outstretched hand seen following a road traffic accident or fall. Most of these fractures are treated either conservatively or by closed reduction and immobilization in cast. In some cases, internal fixation by K-wiring may be required. We conducted this study to analyzed outcome of distal end radius fracture in pediatric age group who were treated by immobilization alone, by closed reduction and immobilization and closed reduction with internal fixation by K-Wire and immobilization in cast. Aims and Objectives: 1 . To analyze outcome of distal end radius fracture in pediatric age group. 2. To study complications in children presenting with distal end radius fracture. Materials and Methods: This was an observational study conducted in the department of orthopedics of a tertiary care medical college. 60 pediatric patients with distal radius fractures and treated either by conservative management or by surgical intervention were included in this study on the basis of a predefined inclusion and exclusion criteria. Gender distribution, mean age and mechanism of injury in the affected cases were analyzed. Patients were treated either by immobilization alone, by closed reduction and immobilization and closed reduction with internal fixation by $\mathrm{K}$-Wire and immobilization in cast. Patients were followed up for 8 weeks. Complications and time for complete union was assessed during follow up visits. Functional outcome was assessed by QuickDash Score. Results: Out of these 60 patients there were $52(86.66 \%)$ males and $8(13.33 \%)$ females with a male to female ratio of 1:0.15. The mean age of affected cases in Boys and Girls was found to be $13.09+/-2.93$ years and $12.5+/-3.64$ years respectively. Dominant hand was involved in $41(68.33 \%)$ whereas non-dominant hand was involved in remaining $19(31.66 \%)$ cases. In $16(26.67 \%)$ patients only casting was required whereas closed reduction and casting was done in $25(41.67 \%)$ patients in remaining $19(31.67 \%)$ patients closed reduction and K-Wire fixation was done. $42(70 \%)$ patients had excellent functional outcome whereas $9(15 \%)$ patients had good functional outcome and $9(15 \%)$ patients were found to have satisfactory outcome. $4(6.66 \%)$ patients developed pressure sores, $1(1.67 \%)$ patient had stiffness and there was $1(1.67 \%)$ case of pin site infections. All these complications were successfully managed by conservative means. Conclusion: Fractures of distal end of radius in pediatric age group can be managed successfully either by immobilization alone or by closed reduction and casting. Internal Fixation by K-Wires may be required in some cases.
Access this article online

Website:

http://nepjol.info/index.php/AJMS

DOI: 10.3126/ajms.v12i9.37041

E-ISSN: 2091-0576

P-ISSN: 2467-9100

Copyright (c) 2021 Asian Journal of Medical Sciences

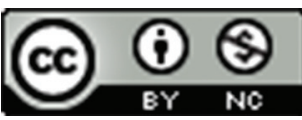

This work is licensed under a Creative Commons Attribution-NonCommercial 4.0 International License.

Key words: Distal end radius Fractures; children; closed reduction; K-wire; Outcome

\section{INTRODUCTION}

Fractures involving upper limbs are commonly seen in children and are important cause for which orthopedic consultations are sought. Out of the fractures involving upper limbs distal radius fractures are most common and are usually caused by road traffic accidents or fall from height. ${ }^{1}$ Irrespective of cause of these fractures the 
mechanism of injury remains fairly uniform in majority of the cases and consist of a fall on outstretched hand thereby causing fracture and rotational displacement. Distal radius fractures are more commonly seen in boys as compared to girls and the peak incidence is seen in between age group of $10-14$ years. ${ }^{2}$ Unlike in adults in whom complete fractures are common in pediatric age group fracture types such as greenstick fractures or buckle (torus) fractures are common. Metaphysical fractures are more common as compared to diaphyseal or epiphyseal one. ${ }^{3}$

The patients usually present with history of fall during play or other activity or following road traffic accident. There are classical clinical findings associated with any fractures like pain, local swelling and deformity. ${ }^{4}$ Physical examination may reveal swelling, crepitus or exposed bone in cases of open fractures. It's essential that presence of compartment syndrome or neurovascular injury is ruled out by appropriate clinical examination and investigations. ${ }^{5}$ The evaluation of these patients included antero-posterior as well as lateral radiographs of wrist, forearm and elbow. Computerized tomography with $3 \mathrm{D}$ reconstruction may be needed in cases of intra-articular fractures but its routine use should be discouraged in children because it involves risks associated with ionizing radiation. ${ }^{6}$

Management of these fractures involves proper alignment and immobilization which can be achieved in majority of the patients by conservative means. Most undisplaced or minimally displaced fractures are usually managed conservatively by immobilization in cast for 4-6 weeks. ${ }^{7}$ However many patients in whom the fractures are unstable or there are complex fractures and in whom loss of reduction has occurred surgical intervention is needed. In routine orthopedics practice pediatric patients with distal radius fractures are surgically managed if non-surgical management is not able to produce or maintain satisfactory alignment. $^{8}$

One of the challenges faced by orthopedicians while treating children presenting with distal radius fractures is to maintain acceptable reduction and preventing redisplacement and re-angulation during cast treatment which is seen in many pediatric cases with distal radius fractures. ${ }^{9}$ Increased incidences of unacceptable displacement of fractures in pediatric age group makes it imperative that all these cases are evaluated properly and surgical intervention be undertaken whenever necessary. Follow up of patients who had been managed conservatively as well as by surgical interventions is an extreme important part of management and mainly focuses on finding out patients in whom there is displacement of fracture requiring further manipulation and internal fixation. ${ }^{10}$
We conducted this study of 60 pediatric patients presenting with distal radius fractures who were treated either by conservative means or by surgical interventions. These patients were evaluated for outcome as well as complications during follow up period.

\section{MATERIALS AND METHODS}

This was an observational study conducted in the department of orthopedics of a tertiary care medical college located in a rural area. Sixty pediatric patients with distal radius fractures and treated either by conservative management or by surgical intervention were included in this study on the basis of a predefined inclusion and exclusion criteria. Demographic details such as age, Sex and area of residence was noted. A detailed history was taken in all the cases in terms of cause and mechanism of injury, duration since injury and to ascertain possibility of polytrauma. A detailed clinical examination was done in all the cases so as to find out the site and type of fracture and to rule out presence of fractures at other sites.

A detailed assessment of injured limb with regards to possibility of neurovascular injury was done immediately upon arrival. Primary immobilization of involved limb was done patients were then sent to department of Radiodiagnosis for imaging. Antero-posterior and true lateral views of injured limb were taken. $3 \mathrm{D}$ computerized tomography was done in selected cases. Cases in whom there was an acute undisplaced fracture an above elbow slab was given for 3 days and patients were reviewed after 3 days. A review X Ray was done and above elbow slab was converted into above elbow cast keeping in mind casting index. All patients in whom surgical intervention was planned underwent basic investigations such as complete blood count, Renal function tests (Blood urea and serum creatinine levels), Hepatic function test (Serum Bilirubin, SGOT, and SGPT), Blood group and Rh typing, bleeding time, clotting time and prothrombin time.

In cases of undisplaced fractures patients were treated by cast immobilization. Closed reduction followed by casting was done in cases in whom satisfactory alignment was achieved by closed reduction. In remaining cases closed reduction with internal fixation by $\mathrm{K}$ wiring was done. Closed reduction only or closed reduction with internal fixation by K-Wires was done under short general anesthesia. Utmost importance was given to achieve acceptable reduction taking into account remodeling capacity (20-30 degree below 10 years of age and 5-15 degrees above 10 years of age). After surgery patients were above elbow cast. X-ray was done to ascertain achievement of satisfactory reduction. The plaster was removed after duration of 3 weeks. Physiotherapy 
and exercises were started after removal of cast. Repeat AP and Lateral radiographs were taken 4 weeks. Physiotherapy was continued for further 4-6 weeks. Functional outcome was assessed by Quick-Disabilities of Arm, Shoulder and Hand (Quick-DASH) scores. Patients were followed up for 8 weeks and outcome was assessed for functional outcome, presence of complications, achieved range of motion and time to union.

A statistical analysis was done using SSPS 21.0 software and $\mathrm{p}$ value less than 0.05 were taken as statistically significant.

\section{Inclusion criteria}

1. Patients presenting with isolated distal radius fractures.

2. Age from 5- 18 years.

3. Informed written consent obtained from parents or guardians.

\section{Exclusion criteria}

1. Patients presenting with multiple fractures.

2. Age less than 5 or more than 18 years.

3. Parents/Guardians Refused consent to be part of study.

4. Pathological Fractures.

5. Patients on long term steroids and immunosuppressant.

6. Patients having any pathology likely to hamper bone remodeling such as parathyroid disorders etc.

7. Patients who were lost to follow up.

\section{RESULTS}

The study comprised of 60 pediatric patients having isolated distal radius fractures who were either treated conservatively or by surgical intervention. Out of these 60 patients there were $52(86.66 \%)$ males and $8(13.33 \%)$ females with a male to female ratio of 1:0.15 (Figure 1).

The analysis of the age group of the patients showed that the most common affected age group amongst boys was $11-14$ years $(46.67 \%)$ followed by above 14 years $(26.67 \%)$ (Table1). Relatively fewer patients were present in the age group of 5-10 years $(13.33 \%)$. Amongst girls most common affected age group was also found to be between $11-14$ years $(8.33 \%)$ followed by $>14$ years $(3.33 \%)$. The mean age of affected cases in Boys and Girls was found to be $13.09+/-2.93$ years and $12.5+/-3.64$ years respectively. The mean age was found to be comparable in both the groups with no significant difference (Table 1).

The analysis of patients on the basis of mechanism of injury showed that in majority of the cases $(88.33 \%)$ fall on outstretched hand was the most common cause of injury. In remaining $7(11.66 \%)$ cases road traffic accidents was the cause of fracture (Figure 2).

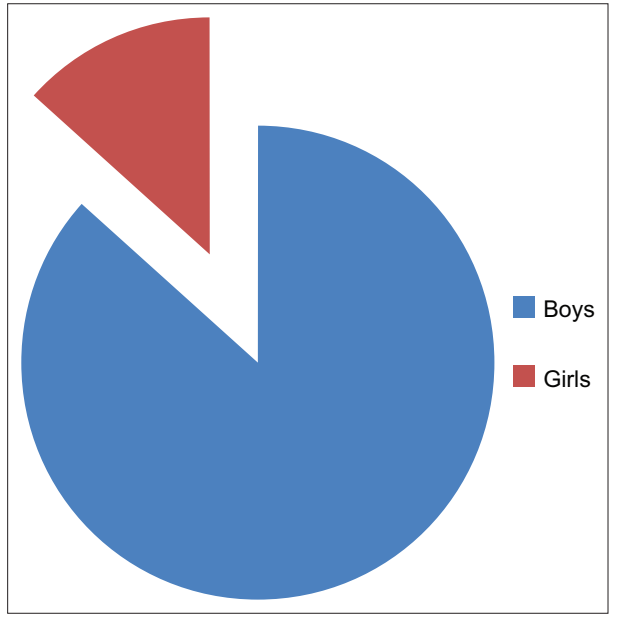

Figure 1: Gender distribution of studied cases

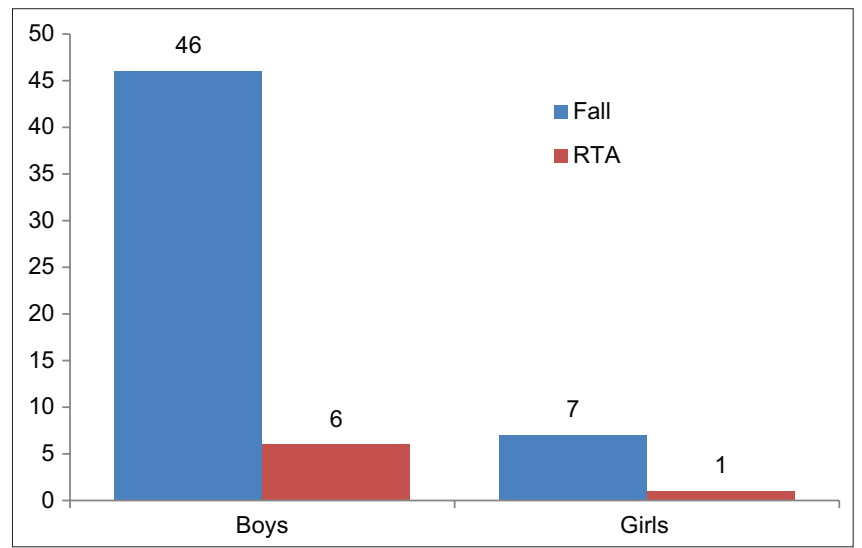

Figure 2: Mechanism of injury in studied cases

\begin{tabular}{|c|c|c|c|c|}
\hline \multirow[t]{2}{*}{ Age } & \multicolumn{2}{|c|}{ Boys } & \multicolumn{2}{|c|}{ Girls } \\
\hline & $\begin{array}{l}\text { No of } \\
\text { cases }\end{array}$ & Percentage & $\begin{array}{l}\text { No of } \\
\text { cases }\end{array}$ & Percentage \\
\hline $5-10$ years & 8 & $13.33 \%$ & 1 & $1.67 \%$ \\
\hline $11-14$ years & 28 & $46.67 \%$ & 5 & $8.33 \%$ \\
\hline$>14$ years & 16 & $26.67 \%$ & 2 & $3.33 \%$ \\
\hline Total & 52 & $86.66 \%$ & 8 & $13.33 \%$ \\
\hline $\begin{array}{l}\text { Mean Age } \\
P=0.22(\mathrm{No}\end{array}$ & \multicolumn{2}{|c|}{$13.09+/-2.93$} & \multicolumn{2}{|c|}{$12.5+/-3.64$} \\
\hline
\end{tabular}

Out of the 60 studied cases dominant hand was involved in $41(68.33 \%)$ whereas non-dominant hand was involved in remaining 19 (31.66 \%) cases (Figure 3).

In $16(26.67 \%)$ patients only casting was required whereas closed reduction and casting was done in 25 (41.67\%) patients in remaining $19(31.67 \%)$ patients closed reduction and $\mathrm{K}$-Wire fixation was done (Table 2).

Patients were followed up for 8 weeks and during follow up visits patients were evaluated for functional outcome, time of union, range of motion achieved as well as occurrence 
of complications. The analysis of patients for time taken for union showed that out of 60 patients 41 (68.33\%) patients had complete union at the time of 4 weeks follow up. Out of remaining $19(31.67 \%)$ patients $15(25 \%)$ had union at 6 weeks and remaining 4 (6.67\%) patients showed complete union at the time of 8 weeks follow up (Figure 4).

The analysis of the patients on the basis of achieved range of motions showed that at 6 weeks follow up visit $24(40 \%)$ patients had already achieved complete range of motion whereas during 6 weeks follow up visits all remaining $26(60 \%)$ patients also showed complete range of motion (Table 3).

The analysis of Quick-DASH which takes into account daily tasks such as opening jar, presence or absence of pain, tingling, sleep disturbance, ability to socialize, ability to perform relatively heavy chores, ability to carry a bag and limitation in routine work. The analysis of functional outcome on the basis of quick DASH scores was assessed

\begin{tabular}{lcc}
$\begin{array}{l}\text { Table 2: Management of children with distal } \\
\text { radius fracture }\end{array}$ & No of Patients & Percentage \\
\hline Management & 16 & $26.67 \%$ \\
\hline Immobilization in Cast & 25 & $41.67 \%$ \\
Closed Reduction and Cast & 19 & $31.67 \%$ \\
Closed Reduction and & & \\
K-Wire fixation & 60 & $100 \%$ \\
Total & & \\
\hline
\end{tabular}

\begin{tabular}{|c|c|c|c|c|}
\hline \multirow[t]{3}{*}{ Follow Up visit } & \multicolumn{4}{|c|}{ Complete Range of Motion } \\
\hline & \multicolumn{2}{|c|}{ Achieved } & \multicolumn{2}{|c|}{ Not Achieved } \\
\hline & Number & $\%$ & Number & $\%$ \\
\hline 6 weeks & 24 & $40 \%$ & 26 & $60 \%$ \\
\hline 8 weeks & 60 & $100 \%$ & 0 & 0 \\
\hline
\end{tabular}

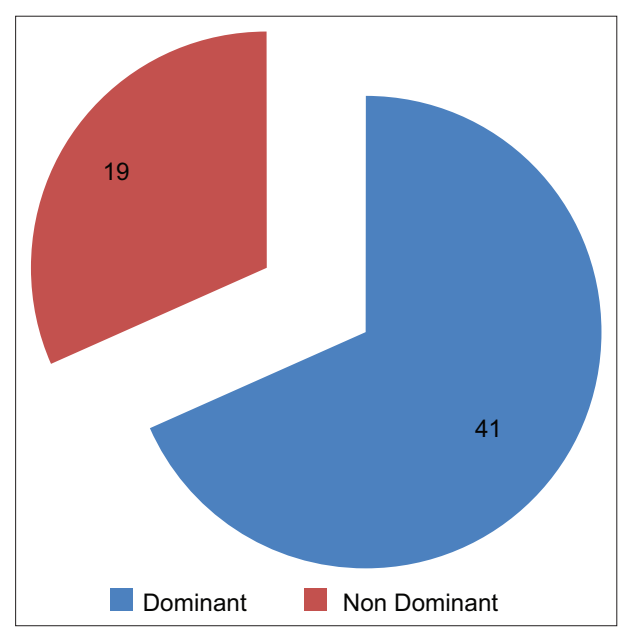

Figure 3: Affected (Dominant Vs Non-Dominant) hand at the time of 8 weeks follow up. It showed that $42(70 \%)$ patients had excellent functional outcome whereas $9(15 \%)$ patients had good functional outcome and $9(15 \%)$ patients were found to have satisfactory outcome. There was no patient with poor outcome as assessed on the basis of Quick-DASH scores (Figure 5).

The analysis of complications in studied cases showed that out of 60 treated cases $54(90 \%)$ patients had no complications. 4 (6.66\%) patients developed pressure sores, $1(1.67 \%)$ patient had stiffness and there was $1(1.67 \%)$

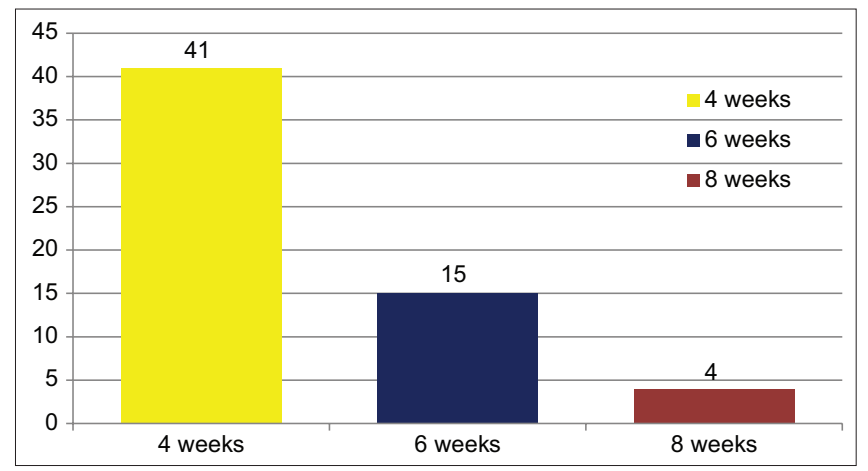

Figure 4: Time for complete union

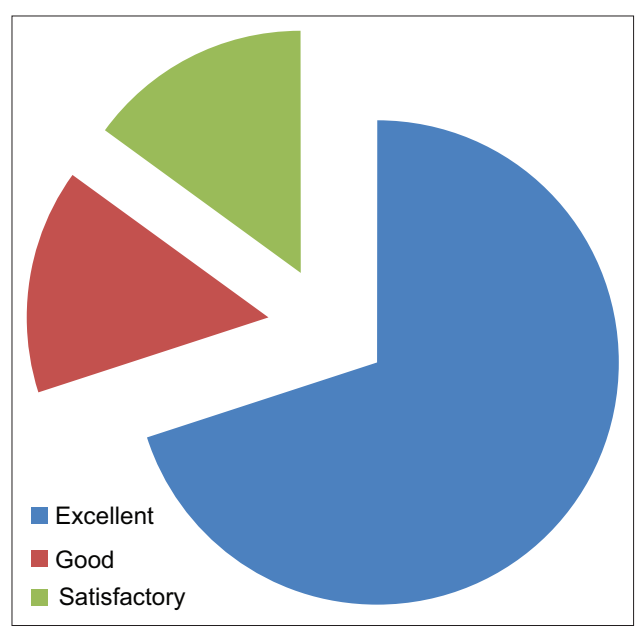

Figure 5: Outcome as assessed by Quick-DASH score

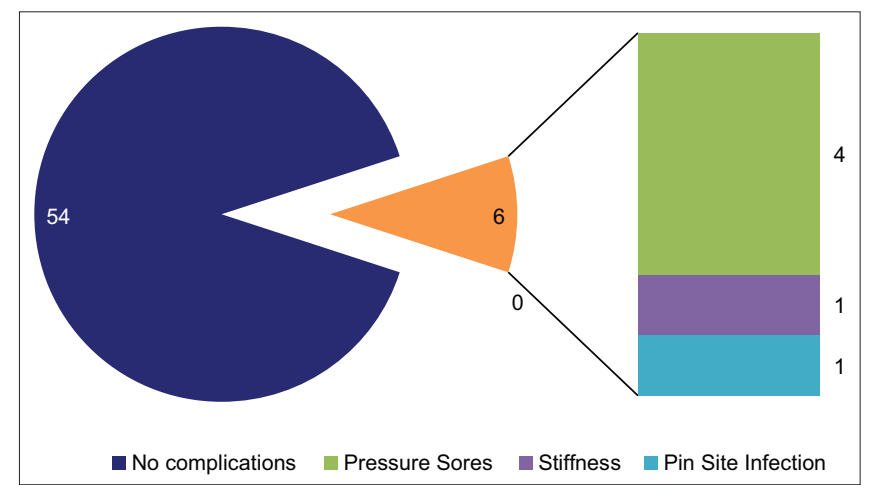

Figure 6: Complications in the studied cases 
case of pin site infections (Figure 6). All these patients were conservatively by physiotherapy and appropriate antibiotics were given to patient with pin site infection to which he responded well.

\section{DISCUSSION}

This study comprised of 60 pediatric patients with isolated distal radius fracture. Out of these 60 patients there were $52(86.66 \%)$ males and $8(13.33 \%)$ females with a male to female ratio of 1:0.15. Randsborg PH et al., conducted a retrospective analysis of 305 distal radius fractures in patients aged less than 16 years. ${ }^{11}$ The authors found that $172(56 \%)$ of the 305 children were boys and remaining $133(44 \%)$ were girls. Similar male preponderance in the incidence of distal radius fracture was also reported by the authors such as Orland KJ et al., ${ }^{12}$ and Syurahbil AH et al. ${ }^{13}$

In our study the mean age of affected cases in Boys and Girls was found to be $13.09+/-2.93$ years and $12.5+/-3.64$ years respectively. Sengab A et al., performed a meta-analysis of 3 randomized controlled trials and 3 cohort studies, analyzing 197 patients treated with cast immobilization alone and 185 with additional K-wire fixation. ${ }^{14}$ In this meta-analysis the authors found that the mean age of the patients included in the studies was $8-13$ years and the majority of the affected cases were male. These findings were also similar to our study.

The mechanism of injury seen in patients with distal radius fracture remains fairly uniform in children as well as adult and fall on outstretched hand remains the most common mechanism of injury in affected cases. Kalantari A et al., conducted a prospective study of 54 patients with displaced fractures of the distal third of the radius with or without ulnar fractures were managed by closed reduction and Percutaneous Kirschner-wire fixation. ${ }^{15}$ The authors found that the most common mechanism of injury in the studied cases was fall on outstretched hand. IN this study mode of injury was fall on outstretched hand in 39 patients and RTA in the other 15 patients. These findings were similar to the findings of our study. Fall on outstretched hand was found to be the most common mode of injury in other studies conducted by Alemdaroğlu KB et al., ${ }^{16}$ and Nellans $\mathrm{KW}$ et al as well. ${ }^{17}$

In our study $16(26.67 \%)$ patients required casting only whereas closed reduction and casting was done in $25(41.67 \%)$ patients and in remaining $19(31.67 \%)$ patients closed reduction and $\mathrm{K}$-Wire fixation was done. In our study out of 60 patients $41(68.33 \%)$ patients had complete union at the time of 4 weeks follow up. Out of remaining $19(31.67 \%)$ patients $15(25 \%)$ had union at 6 weeks and remaining 4 (6.67\%) patients showed complete union at the time of 8 weeks follow up. In a similar study comprising of 32 patients Kuloor SB et al., found that $56 \%$ of the patients had union at 6 weeks and all patients had union at 8 weeks follow up visit. These findings were similar to the findings of our study. ${ }^{18}$

Finally in our study functional outcome as assessed on the basis of Quick DASH score showed that $42(70 \%)$ patients had excellent functional outcome whereas $9(15 \%)$ patients had good functional outcome. 9 (15\%) patients were found to have satisfactory outcome. In our study $54(90 \%)$ patients had no complications. Four $(6.66 \%)$ patients developed pressure sores, $1(1.67 \%)$ patient had stiffness and there was $1(1.67 \%)$ case of pin site infections. In a similar study Gohil P et al., assessed outcome of children with distal radius fractures treated by casting, closed reduction and casting as well as closed reduction and $\mathrm{k}$ wire fixation. Functional outcome was assessed by Gartland and Warley's scoring system. ${ }^{19}$ The authors found that 29 patients had excellent result and one patient had fair result. There was no patient with unsatisfactory outcome and 3\% patients developed pin site infection which was managed successfully by conservative means. ${ }^{20}$

One of the limitations of our study was small number of cases included in this study but given the rural area where our institute is located the incidence of trauma secondary to road traffic accidents and overall traumatic injuries is less. Moreover, some of the cases were also excluded from the study as they were lost to follow up.

\section{CONCLUSION}

Fractures of distal end of radius in pediatric age group can be managed successfully by immobilization alone, by closed reduction and immobilization and closed reduction with internal fixation by K-Wire and immobilization in cast with excellent outcome in majority of cases.

\section{REFERENCES}

1. Otayek S, Ramanoudjame M and Fitoussi F. Les fractures de l'extrémitédistale du radius chez l'enfant [Distal radius fractures in children]. Hand Surg Rehabil. 2016; 35S: S150-S155. French. https://doi.org/10.1016/j.hansur.2016.02.013

2. Nellans KW, Kowalski E and Chung KC. The epidemiology of distal radius fractures. Hand Clin. 2012;28(2):113-125. https:// doi.org/10.1016/j.hcl.2012.02.001

3. Sankar WN, Beck NA, Brewer JM, Baldwin KD and Pretell JA. Isolated distal radial metaphyseal fractures with an intact ulna: risk factors for loss of reduction. J Child Orthop. 2011;5(6):459464. https://doi.org/10.1007/s11832-011-0373-z

4. Loi F, Córdova LA, Pajarinen J, Lin TH, Yao Z and Goodman SB. Inflammation, fracture and bone repair. Bone. 2016; 86:119-130. 
https://doi.org/10.1016/j.bone.2016.02.020

5. Hwang RW, de Witte PB and Ring D. Compartment syndrome associated with distal radial fracture and ipsilateral elbow injury. J Bone Joint Surg Am. 2009;91(3):642-645.

https://doi.org/10.2106/JBJS.H.00377

6. Adams JE, Engelke K, Zemel BS and Ward KA. International Society of Clinical Densitometry. Quantitative computer tomography in children and adolescents: the 2013 ISCD Pediatric Official Positions. J Clin Densitom. 2014;17(2): 258-274.

https://doi.org/10.1016/j.jocd.2014.01.006

7. Zhu M, Lokino ES, Chan CS, Gan AJ, Ong LL and Lim KB. Cast immobilisation for the treatment of paediatric distal radius fracture: fibreglass versus polyolefin. Singapore Med J. 2019;60(4):183-187. https://doi.org/10.11622/smedj.2018118

8. Price CT. Surgical management of forearm and distal radius fractures in children and adolescents. Instr Course Lect. 2008; 57:509-514.

9. Zamzam MM and Khoshhal KI. Displaced fracture of the distal radius in children: factors responsible for redisplacement after closed reduction. J Bone Joint Surg Br. 2005;87(6):841-843. https://doi.org/10.1302/0301-620X.87B6.15648

10. Alagöz $E$ and Güleç MA. Factors affecting re-displacement in pediatric forearm fractures and the role of cast indices. Jt Dis Relat Surg. 2020;31(1):95-101. https://doi.org/10.5606/ehc.2020.71523

11. Andsborg $\mathrm{PH}$ and Sivertsen EA. Distal radius fractures in children: substantial difference in stability between buckle and greenstick fractures. Acta Orthop. 2009;80(5):585-589. https://doi.org/10.3109/17453670903316850

12. Orland KJ, Boissonneault A, Schwartz AM, Goel R, Bruce RW and Fletcher ND. Resource Utilization for Patients With Distal Radius Fractures in a Pediatric Emergency Department. JAMA Netw Open. 2020;3(2): e1921202. https://doi.org/10.1001/jamanetworkopen.2019.21202

13. Syurahbil AH, Munajat I, Mohd EF, Hadizie D and Salim AA. Displaced Physeal and Metaphyseal Fractures of Distal Radius in Children. Can Wire Fixation Achieve Better Outcome at Skeletal Maturity than Cast Alone?. Malays Orthop J. 2020;14(2):28-38. https://doi.org/10.5704/MOJ.2007.008

14. Sengab A, Krijnen $P$ and Schipper IB. Displaced distal radius fractures in children, cast alone vs additional K-wire fixation: a meta-analysis. Eur J Trauma Emerg Surg. 2019; 45(6):10031011. https://doi.org/10.1007/s00068-018-1011-y

15. Kalantri A, Barod S, Kothari D, Kothari A and Bhambani P. Closed Reduction, Percutaneous Kirschner Wire Fixation and Cast Immobilisation of Distal Radius Fracture- A Prospective Observational Study. JMSCR. 2017; 5(6): 23707-23718. https://doi.org/10.18535/jmscr/v5i6.150

16. Alemdaroğlu KB, Iltar S, Cimen O, Uysal M, Alagöz E and Atlihan D. Risk factors in redisplacement of distal radius fractures in children. J Bone Joint Surg Am. 2008;90(6):12241230. https://doi.org/10.2106/JBJS.G.00624

17. Nellans KW, Kowalski E and Chung KC. The epidemiology of distal radius fractures. Hand Clin. 2012;28(2):113-125. https:// doi.org/10.1016/j.hcl.2012.02.001

18. Kuloor SB, Mattam AJ, Shareef AJ and Sudeep A. Paediatric forearm refractures- management and outcome: a prospective study. Int J Res Orthop. 2019; 5:408-411.

https://doi.org/10.18203/issn.2455-4510.IntJResOrthop 20191444

19. Gartland JJ Jr and Werley CW. Evaluation of healed Colles' fractures. J Bone Joint Surg Am. 1951;33-A (4):895-907. https:// doi.org/10.2106/00004623-195133040-00009

20. Gohil P, Jain D, Raut S, Malviya P, Vieira A and Agrawal T. A prospective study of management of distal end of radius fracture in children. Int J Res Orthop. 2020;6:803-809.

\footnotetext{
Author's contributions:

VP - Concept and design of the study; prepared first draft of manuscript, Interpreted the results; reviewed the literature and manuscript preparation;

AA - Concept, coordination, review of literature and manuscript preparation; VA - Statistically analyzed and interpreted, preparation of manuscript and revision of the manuscript.

Work Attributed to:

SSPM Medical College and Lifetime hospital, A.P. Padve, Kasal - Malvan Rd, Ranbambuli, Maharashtra, India.

Orcid ID:

Dr Vishwas Sharad Phadke - (i) https://orcid.org/0000-0002-4672-4608

Dr. Ajaykumar Ramlu Allamwar - (1) https://orcid.org/0000-0001-6193-7209

Dr. Vaibhav Vinayak Antrolikar - (1) https://orcid.org/0000-0002-3429-3644

Source of Funding: None, Conflict of Interest: None.
} 